\title{
EXPECTATIVAS DOS EMPREENDEDORES DE STARTUPS EM RELAÇÃO ÀS COMPETÊNCIAS ESPERADAS NA CONTRATAÇÃO DE EMPREGADOS
}

Caio Flavio Stettiner ${ }^{1}$

Edinicio Oliveira Lima ${ }^{1}$

Eliane Maria Pires Giavina Bianchi ${ }^{2}$

${ }^{1}$ UNIFACCAMP - CENTRO UNIVERSITÁRIO CAMPO LIMPO PAULISTA

${ }^{2}$ Centro Universitário Campo Limpo Paulista / Unifaccamp 


\section{EXPECTATIVAS DOS EMPREENDEDORES DE STARTUPS EM RELAÇÃO ÀS COMPETÊNCIAS ESPERADAS NA CONTRATAÇÃO DE EMPREGADOS.}

Resumo: O presente estudo está vinculado à área de conhecimento que trata das competências no âmbito organizacional. Trata, particularmente, daquelas competências requeridas no exercício do trabalho no ambiente da Startup. Propõe-se a levantar as expectativas de empreendedores desse ambiente, em relação aos atributos de competência esperados por eles na oportunidade da contratação de colaboradores para o seu negócio. Espera-se com isso, identificar as principais características que devem moldar o perfil desse profissional, sejam elas na esfera organizacional ou individual, sejam de ordem técnica ou de caráter social ou comportamental. Sob a inspiração de perspectivas teóricas como as de McClelland e Spencer e Spencer, o estudo tem por objetivo identificar a percepção dos empreendedores de impacto sobre as competências requeridas do candidato ao emprego no mundo de negócio da Startup. Metodologicamente, o estudo vale-se de uma abordagem qualitativa com o estudo multicaso e observação direta na incubadora e aceleradora INOVABRA mantida pelo Banco Bradesco e na aceleradora Oxigênio mantida pela Seguradora Porto Seguro. Oportunidade em que foram submetidas a entrevistas fundadores e gestores de empreendimentos de impacto abrigados nestas incubadoras, compondo uma amostra do tipo "bola de neve", por tratar-se de uma população com baixa ocorrência e de acesso restrito. Em vista disso, a revisão da literatura apresenta a caracterização da tipologia de negócio Startup, concepções sobre competência e assuntos subjacentes que possam contribuir na compreensão do objeto estudado. Da análise e discussão do estudo restaram indicadas algumas aptidões mais recentes requeridas no mundo de negócios das startups, o que deu embasamento a algumas considerações críticas a respeito de novas competências que poderiam estar sendo reivindicadas no atual mercado de trabalho. Com a expectativa de alertar para aspectos de interesse de candidatos, de selecionadores e de estudiosos, o estudo atende ao que lhe deu ensejo, na medida em que traz indícios sobre o trabalho no mercado de alto impacto e indicativos de um vasto espaço de lacunas a serem investigadas num horizonte próximo de pesquisa.

Palavras-chave: Empreendedorismo. Empreendedores. Colaboradores. Competências.

Abstract:This study is linked to the area of knowledge that deals with competences in the organizational scope. It deals in particular with those skills required in the Start Up work environment. It is proposed to raise the expectations of entrepreneurs in this environment, regarding the competence attributes expected by them in the opportunity to hire employees for their business. It is hoped with this, to identify the main characteristics that should shape the profile of this professional, whether in the organizational or individual sphere, whether technical or social or behavioral. Inspired by theoretical perspectives such as those of McClelland and Spencer and Spencer, the study aims to identify entrepreneurs 'perceptions of the impact on job seekers' required skills in Startup's business world. Methodologically, the study uses a qualitative approach with the multi-case study and direct observation of the INOVABRA incubator and accelerator maintained by Banco Bradesco and the Oxygen accelerator maintained by Seguradora Porto Seguro. Opportunity in which they were subjected 
to interviews founders and managers of impact ventures housed in these incubators, composing a "snowball" type sample, because it is a population with low occurrence and restricted access. In view of this, the literature review presents the characterization of the Startup business typology, conceptions about competence and underlying issues that may contribute to the understanding of the studied object. The analysis and discussion of the study indicated some of the most recent skills required in the startup business world, which underpinned some critical considerations about new skills that could be claimed in today's job market. With the expectation of alerting to aspects of interest of candidates, selectors and scholars, the study responds to what has given rise to it, as it brings evidence about the work in the high impact market and indicative of a wide space of gaps to be investigated in a near research horizon.

Keywords: Entrepreneurship, Entrepreneurs, Employees, Competences

\section{INTRODUÇÃO}

Ultimamente o tema competência vem pautando de forma recorrente o debate nas esferas acadêmica e empresarial. A concepção, a formação e a gestão da competência, estão vinculados a diferentes interpretações nas extensões organizacional, individual e regional. O senso comum atribui ao termo competência, a capacidade que uma pessoa tem de realizar algo. Os dicionários (Webster e Aurélio, por exemplo) associam o termo à condição da pessoa dispor de conhecimento e funcionar de forma correta para realizar uma tarefa. Eles vinculam à expressão atributos como: aptidão, habilidade, capacidade de julgamento e idoneidade.

Num cenário em que o mundo do trabalho vem centrando seus esforços no desenvolvimento da competência como fator determinante do desempenho ideal, o perfil requerido, tanto no aspecto pessoal quanto no profissional, vem exigindo das pessoas, novas qualificações, tempestividade, realismo, criatividade, indivíduos inovadores e harmonizados com o avanço da ciência e tecnologia. No âmbito organizacional, desenvolver competência significa combinar adequadamente conhecimento, habilidades e atitude.

Por trás dessas constatações, desencadeiam-se muitas discussões sobre o futuro do emprego. Questões como o papel do empregado e quais competências ele deve dominar, aparecem, por exemplo, no estudo de Zarifian (2008) quando alerta que a tendência do trabalho é tornar-se um reflexo direto da competência que o empregado tem. Isso permite inferir a relevância da competência na execução do trabalho e seu papel decisivo na seleção para emprego.

Partindo desse quadro e pensando sobre a empregabilidade no novo e menos convencional campo de trabalho desempenhado no ambiente das empresas que atuam nos chamados negócios de alto impacto, o presente estudo vincula-se à discussão sobre o processo de seleção e contratação de empregados numa empresa do tipo startup. Seu propósito é contribuir com o exame de possíveis diferenças na percepção de competência entre o recrutamento nessa área e a percepção de acordo com as categorias teóricas apresentadas por Spencer e Spencer (1973), nos moldes tradicionais.

A expectativa que se adota então, é de levantar o debate sobre a compreensão de competência nas suas dimensões técnica, comportamental e social, a partir da indagação sobre as competências esperadas pelos empreendedores nos negócios de startups, na oportunidade da contratação de seus empregados. Espera-se com esse exercício empírico, levantar possíveis 
evidências de diferenças e semelhanças entre a modelagem teórica tomada por referência e a percepção dos empreendedores de startups.

Vislumbrando melhor esclarecimento sobre a percepção dos empreendedores dirigentes de startups a respeito da competência, a pesquisa tem por objetivo levantar as expectativas preponderantes desses empreendedores em relação aos atributos de competência de candidatos a um posto de trabalho.

O objetivo proposto terá como desdobramento específico a ponderação qualitativa dos dados relativos às competências técnica, sociais e comportamentais inventariadas, de modo que essas medidas possam revelar atributos com maior ou menor importância na elaboração de um quadro de competências para o trabalho no ambiente de negócio de uma startup.

Nesses termos, o estudo faz um breve resgate do debate teórico sobre os assuntos que possam dar suporte à compreensão do objeto estudado, contemplando seções sobre a competência, sobre a caracterização da tipologia de negócio Startup e sobre aspectos da gestão das pessoas, implícitos no desenvolvimento da competência.

\section{COMPETÊNCIA}

De modo geral, as acepções encontradas nos dicionários associam o termo competência a uma aptidão para cumprir alguma tarefa ou função ou associam a uma atribuição legal. A literatura do mundo organizacional, frequentemente, indica a relação entre os conceitos de Habilidade e Competência. Colocar em prática as teorias aprendidas seria uma habilidade, enquanto um conjunto mais amplo envolvendo Conhecimento, Habilidade e Atitude (CHA) formam a expressão da competência.

Esse ideograma "CHA" foi descrito por Scott B. Parry em sua obra "The quest for competencies" de 1996, para explicar a concepção de competência: O C significa Conhecimento sobre um tema escolhido. Isso significa a pessoa dominar um Know-how definido a respeito de algo que possua valor para si mesma e para a empresa , é o saber. O H significa Habilidade para executar algo com o conhecimento que se dispõe. Diz respeito à pessoa conseguir fazer utilização real do conhecimento que têm, produzindo algo efetivamente. o saber fazer.

O A significa Atitude com iniciativa positiva e pró ativa. Diz respeito ao indivíduo não aguardar os acontecimentos ou alguém ter que ministrar ordens, e fazer o que deve ser feito por iniciativa própria, o querer fazer.

O estudioso americano Richard Bolles fala de "competência profissional" referindo-se ao exercício da competência no contexto organizacional e no mundo do trabalho, significando o perfil que mostra a aptidão de uma pessoa para realizar as tarefas próprias daquele meio.

No ambiente competitivo e globalizado atual, o conceito de competência passa a abranger a ideia de obtenção de resultados, comenta o pesquisador. Com esta abordagem, novos atributos são adicionados ao significado de competência, ampliando seu conceito com a inclusão dos termos (V) de Valores e (E) de Emoção, Entusiasmo, Energia e Entorno, fechando o ideograma com a sigla CHAVE.

O entendimento subjacente é que os valores fundamentam as decisões do indivíduo e determinam a qualidade de suas realizações. Espera-se do profissional competente uma atuação marcada pela ética e pelo respeito aos bons princípios. 
Os Atributos indicadas pela letra "E" fornecem o contexto para a expressão da competência. A competência emocional vem sendo mais requisitada, sobretudo no papel da liderança, que depende de bom relacionamento para o desenvolvimento da equipe. A respeito do entusiasmo o mesmo autor tece comentário elevando a importância do entusiasmo pelo trabalho, justificando que esse exercício traz vigor para a mente e o espírito. Bolles (2006).

Competências são formadas por força do aproveitamento de valores, crenças e experiências acumuladas na cultura que a empresa utiliza para obtenção de vantagens competitivas. No plano individual, portanto, a empresa espera do indivíduo o reforço do seu traço cultural. A propósito, Fleury (2000) ao caracterizar competência resgata em parte a concepção do ideograma "CHA" ao falar sobre o "Saber" e incluir no seu significado a ideia da pessoa ser capaz de arranjar recursos de modo a agregar valor para a organização e ter satisfação pessoal.

Em sua obra "Desenvolvendo Competências Consistentes", Paul C. Green apresenta duas categorias de competências, as individuais e as organizacionais. No plano individual as pessoas acumulam experiências e conhecimentos na sua trajetória profissional, estabelecendo um padrão de competência, que integrada a outras individuais formam a competência organizacional, denominadas pelo pesquisador como competências essenciais ("core competence"). O autor continua esclarecendo que o propósito principal de uma organização está centrado numa forma particular de fazer as coisas, num know-how técnico distinto.

Entre os pioneiros na abordagem das competências essenciais, C.K.Prahalad e Gary Hamel (1990), publicaram na Harvard Business Review um artigo com o título "Core Competence”. De acordo com eles apenas uma pequena parte das competências essenciais possibilitam a organização oferecer um benefício distinto a seus clientes, estabelecendo assim uma vantagem competitiva duradoura.

Parece ficar patente, então, que a boa performance competitiva da organização depende das decisões rotineiras tomadas com base na competência de seus empregados. Neste caso, a gestão por competência apresenta-se como alternativa para o alcance desse desempenho. É o que se pode extrair do entendimento de Prahalad e Hamel (2005).

Como se pode observar diversas definições e tipologias de competências são apresentadas de acordo com as variadas perspectivas dos pesquisadores mencionados. No entanto, eles estão tratando da mesma orientação para o trabalho, donde se destacam alguns aspectos em comum. Entre eles, a classificação de competências em duas categorias: individuas e organizacionais. Prahalad e Hamel (1990) e Green (2000) explicam que o caráter distintivo das competências agrega valor percebido pelo consumidor, conferindo à empresa uma vantagem competitiva.

Ainda em comum entre as diversas concepções de competência individual os autores consideram "hábitos", "atitudes" e "conhecimentos" na caraterização da competência. Duas distinções são apresentadas pelos mesmos autores: Competência comportamental e competência técnica. A primeira diz respeito à atitude de uma pessoa, a segunda à habilidade $\mathrm{e}$ ao conhecimento de uma pessoa no cumprimento de uma função específica.

A depreender do entendimento dos autores examinados, dentre eles, McClelland (1990) e Prahalad \& Hamel (1990), os credos e valores se solidificam formando as convicções do indivíduo. Estas convicções oferecem uma visão de sua identidade e determinam o que ele pode realizar e seu modo de operar no ambiente. Esse modo de ser fundamentado nas crenças, vai repercutir na sua motivação para o trabalho. 
A competência se manifesta e se torna perceptível, segundo esses autores, através do modo peculiar de exercer uma habilidade. Assim a identificação do indivíduo e sua autoestima demarcam os limites de sua competência, pois como já vimos, além da habilidade e do conhecimento, a competência inclui outros elementos de natureza comportamental que revelam o modo de ser particular do indivíduo, elementos esses, inseridos na dimensão atitudinal da competência.

Numa outra abordagem para competência, Le Boterf (2003) enfatiza a associação da competência com a noção de profissionalismo e com uma disposição mais ampla da pessoa para coordenar esforços, em lugar de uma ação isolada. Dentre tantas abordagens possíveis, o quadro seguinte apresenta alguns resumos de diferentes concepções para o termo competência.

Quadro 1. Abordagens conceituais de competência.

\begin{tabular}{|r|c|}
\hline ABORDAGEM & AUTOR \\
\hline $\begin{array}{l}\text { Centrando-se num dote, na ação, na realização e no } \\
\text { arranjo adequado do saber e do fazer, da experiência } \\
\text { acumulada e da postura atitudinal perante as situações. }\end{array}$ & Zarifian, 2008 \\
\hline $\begin{array}{l}\text { Destaca na competência, a importância do } \\
\text { indivíduo ser proativo e mobilizador na solução de } \\
\text { problemas complexos. }\end{array}$ & Le Boterf, 2003 \\
\hline $\begin{array}{l}\text { Enfatizando o aspecto atitudinal, a instrução e a } \\
\text { performance no trabalho, competência é definida como } \\
\text { Conhecimento, Habilidade e Atitude (“CHA”) que } \\
\text { determinam o desempenho do indivíduo. }\end{array}$ & Becker e outros, \\
\hline $\begin{array}{l}\text { Destacando o ato da execução, o resultado e uma } \\
\text { concepção mais abrangente envolvendo a comunicação, a } \\
\text { competência é reflexo do conhecimento, da habilidade e da } \\
\text { integração no contexto do trabalho. }\end{array}$ & Devy-Leboyer, \\
\hline $\begin{array}{l}\text { Reconhece a interdependência entre os elementos } \\
\text { do CHA como determinante para a concretização de } \\
\text { objetivos. }\end{array}$ & Durand, 1998 \\
\hline como fator que distingue as pessoas competentes. & \\
\hline
\end{tabular}




\begin{tabular}{|c|c|}
\hline $\begin{array}{l}\text { Coloca a competência como fruto da noção do } \\
\text { trabalho e não apenas como desenvolvimento de } \\
\text { características como habilidade e saberes. }\end{array}$ & Sandberg, 1996 \\
\hline $\begin{array}{l}\text { Enfatiza a instrução no desenvolvimento da } \\
\text { competência e a possibilidade de sua mensuração mediante } \\
\text { o confronto com determinado padrão. }\end{array}$ & Parry, 1996 \\
\hline $\begin{array}{l}\text { Destaca que a competência } \\
\text { característica cognitiva natural e da } \\
\text { capacidade com a experiência para a realizaçãão de tarefas. }\end{array}$ & Moscovicci, 1994 \\
\hline $\begin{array}{l}\text { Posiciona a competência no centro da estratégia } \\
\text { empresarial e relevante para o alcance de desempenho } \\
\text { superior e desenvolvimento da carreira. }\end{array}$ & $\begin{array}{c}\text { Sparrow e } \\
\text { Bognanno, } 1994\end{array}$ \\
\hline $\begin{array}{l}\text { Enfatizando uma capacidade natural de influenciar, } \\
\text { de realizar e a formação que uma pessoa tem, competência } \\
\text { é abordada como características individuais próprias que } \\
\text { coloca a pessoa numa posição de referência para o } \\
\text { desempenho no trabalho. }\end{array}$ & $\begin{array}{c}\text { Spencer e } \\
\text { Spencer, } 1993\end{array}$ \\
\hline $\begin{array}{l}\text { Destacando uma certa tendência natural, valores e } \\
\text { instrução, aqui competência é definida como o traço } \\
\text { distintivo de alguém que avalia e soluciona problemas; que } \\
\text { é capaz de fazer coisas porque tem habilidade, } \\
\text { responsabilidade e aptidão. }\end{array}$ & Boog, 1991 \\
\hline $\begin{array}{l}\text { Enfatizando o ato da execução e o resultado obtido, } \\
\text { essa concepção define competência como aspecto tácito de } \\
\text { um indivíduo relacionado com um bom desempenho na } \\
\text { execução de uma tarefa ou no resultado de sua atuação em } \\
\text { certa situação. }\end{array}$ & McClelland, 1973 \\
\hline
\end{tabular}

Elaboração dos autores 
Como se pode observar, a literatura registra uma multiplicidade de abordagens conceituais nem sempre consensuais para definir competência. Num momento é abordada como realização (resultado) noutro como processo e assim vai apresentando várias facetas, o que aumenta a dificuldade para traçar uma definição ou fazer a avaliação da competência.

Não obstante essa dificuldade, ganhou força na literatura por sua recorrência, a concepção de competência envolvendo o CHA (Conhecimento, Habilidade e Atitude) defendida por McClelland (1973) e seguida por Spencer e Spencer (1983). Nessa abordagem atributos individuais são relacionados a um alto desempenho numa atividade funcional.

Com esse lastro teórico, Spencer e Spencer (1993) apresentou um conjunto de escalas de competências extraídas de categorias que supostamente refletem a influência sobre os grupos de trabalho e seus resultados no âmbito organizacional. Em linhas gerais, do modelo dos Spencer apresentado no Dicionário de Competências publicado em 1993, pode-se definir competências a partir dos seis grupos descritos na tabela constante da seção número 5 que trata da análise e discussão sobre os dados coletados no presente estudo.

O estudo dos Spencer deriva das pesquisas de McClelland (1973) exposta no artigo seminal "Testing for Competence Rather Intelligence". Vale registrar que McClelland foi orientador do casal Spencer nas suas pesquisas publicadas em periódico de psicologia, sendo os testes baseados em competências amplamente aplicados nos processos de recrutamento e seleção levados a efeito na área de Recursos Humanos.

\section{A STARTUP}

O conceito de startup é polissêmico, registrando uma diversidade de definições. Coloquialmente vem sendo caracterizada como empresa de alta tecnologia. Luger e Koo (2005) na tentativa de conceituar esse tipo de empresa acabou por aderir às definições mais utilizadas, como negócios que são novos, ativos e independentes.

As empresas precisam ser inovadoras para que as sociedades obtenham o desenvolvimento econômico desejado (Schumpeter, 1934 e 1984). Neste sentido, as empresas do tipo startups desempenham importante papel no Ecossistema Empreendedor de um país, uma vez que seu ideário constitui uma fonte significativa de muitas inovações (Hunt, 2013; Gruber et al., 2008; Acs e Audretsch, 1988). A startup é definida como um novo empreendimento com recursos técnicos e financeiros limitados. Blank (2010) define uma startup como "um tipo de organização vinculada a um formato de negócio susceptível de repetição e "escalável". Esse tipo de negócio subordina-se a requisitos tais como novidade e exiguidade e por isso tem dificuldades de acessos a recursos adequados (Freeman et al., 1983; Hannan e Freeman, 1989). A escassez de recursos obriga as empresas principiantes a procurar parceiros externos em diversos estágios de desenvolvimento e comercialização de suas ideias, produtos ou serviços (Teece, 2010; Esteve-Pérez e Rodríguez, 2013).

Aceita pela comunidade acadêmica, a OCDE (2010) define startups como empresas de alto crescimento, caracterizada por dois atributos, o primeiro um grande crescimento em tamanho (usualmente medido pelo aumento de funcionários) de maneira intensa durante o período analisado. Assim, startups são caracterizadas como empresas novas, ativas, independentes, com poucos recursos e com crescimento elevado em um curto período. 
Na complexidade atual de um mercado globalizado, os elementos que fundamentam o modo como as empresas selecionam e contratam seus empregados são as velozes transformações econômicas, as expectativas dos pretendentes do emprego em permanente mutação; as novidades tecnológicas e os novos métodos de avaliar pessoas (ZEUCH, 2016).

A gestão de recursos humanos (GRH) consiste numa abordagem estratégica para gerenciar as relações de emprego. Trata-se da abordagem que enfatiza o desenvolvimento de capacidades e o comprometimento das pessoas como elementos fundamentais para alcançar uma vantagem competitiva sustentável para a organização empresarial ou pública prestadoras de serviços de qualidade. Este desempenho é alcançado por força da implementação de um conjunto de políticas, programas e práticas de emprego integradas, vinculadas dentro de uma organização (BRATTON, J; GOLD; J p.7, 2017).

A gestão de recursos humanos $(\mathrm{GRH})$ cuida dos aspectos relativos às pessoas desde a sua admissão como empregados até o seu gerenciamento nas organizações. As crenças básicas da GRH consideram que as pessoas constituem recurso determinante na obtenção de vantagem competitiva para a empresa, tendo como propósito permanente o aumento do comprometimento do funcionário. Por isso, no entendimento de (Armstrong, M;Taylor, 2014), as decisões de RH são de importância estratégica e devem ser integradas ao planejamento estratégico da Empresa.

Os objetivos da Gestão de Recursos Humanos na visão de Armstrong e Taylor (2014) são: apoiar a empresa na realização de seus objetivos, desenvolvendo e implementando estratégias de recursos humanos $(\mathrm{RH})$ integradas com a estratégia de negócios; contribuir no desenvolvimento de uma cultura organizacional de alto desempenho; prover organização de talentos e pessoas qualificadas e engajadas para suas atividades; fomentar uma relação de emprego positiva entre a equipe.

\section{MÉTODO}

O trabalho vale-se de uma abordagem metodológica qualitativa exploratória do tipo estudo multicaso associado à observação direta. Comesses recursos, visa dar voz aos respondentes (Gill, 2008; Goldenberg, 2004; Lacey, 1999; Vieira \& Zouain, 2004), neste caso, empreendedores fundadores de empreendimentos tecnológicos de alto impacto acelarados pela INOVABRA, instituição do Banco Bradesco e empreendedores da Aceleradora OXIGÊNIO mantida pela Grupo Porto Seguro.

Inaugurado em meados de 2018 o INOVABRA é um espaço voltada a inovação e criação de negócios de alto impacto, operando como uma extensão do conceito de inovação que o Bradesco vem se empenhando em adotar na última década. A premissa inicial do projeto era conectar startups com negócios que servissem às necessidades de transformação digital do Banco. Posteriormente o projeto ampliou seu escopo assumindo o propósito mais amplo de "incentivar a inovação de alto impacto e gerar valor para empresas e para sociedade por meio da colaboração entre startups, grandes empresas, consultores e mentores, investidores e tech partners" (Site: www.inovabra.com.br).

Concebido como um ecossistema, o INOVABRA foi criado para estimular a inovação interna na instituição e no seu meio externo. Formado por oito programas complementares ligados pelo princípio da inovação, eles possuem regras e funcionamento distintos e complementares em seus objetivos e contam com: Habitat, espaço físico de $22.000 \mathrm{~m} 2$ onde se localiza o ecossistema empreendedor; Ventures, fundo de capital próprio do Bradesco com 
capital de US\$100 milhões para investimento em novos negócios; Lab, ambiente de $1700 \mathrm{~m} 2$ com 16 laboratórios de alta tecnologia para desenvolvimento de protótipos; Inteligência Artificial, centro de excelência com equipe voltada ao desenvolvimento desta tecnologia; Polos: programa de inovação interno do Bradesco fundado para o estímulo do intraempreendedorismo das diversas áreas de negócios do banco; Internacional formado por ambiente colaborativo sediado em Nova York, nos Estados Unidos da América; o Hub que funciona como uma plataforma digital que conecta os empreendedores do INOVABRA aos demais parceiros do Ecossistema Empreendedor e Inovador do Brasil. Por fim, tem-se o programa Startups cujo objetivo é o fomento de inovação aberta para a formação de parcerias colaborativas entre o Banco Bradesco e Startups em estágios iniciais (Site: www.inovabra.com.br, p.3).

A Aceleradora Oxigênio, por sua vez, procura fomentar startups que possuam soluções inovadoras e criem oportunidades de negócios em conjunto com o rol de negócios do Grupo Porto Seguro. A Acelaradora oferece às startups selecionadas designer, consultorias jurídicas, espaço em servidores (AWS, Google e IBM), desenvolvimento de parcerias, promovendo reuniões com outras empresas parceiras e clientes do Grupo Porto Seguro, para estimular novas oportunidades de negócios. Atualmente seu programa é "equity free", ou seja, as startups não vendem parte de sua participação societária para serem acelerada o que permite a participação de startups em diferentes estágios de crescimento. Vale ressaltar que a atual gestão da Aceleradora Oxigênio está sendo efetuada pela Liga Ventures, especialistas em programas de aceleração corporativa (www.liga.ventures). (www.oxigenioaceleradora.com.br ).

A neutralidade em relação à seleção e categorização dos sujeitos marcou a composição da amostra de 11 empreendedores entrevistados, sendo esta quantidade delimitada pelo ponto de saturação, ou seja, as informações coletadas e apresentadas pelos entrevistados se mostraram suficientes e evidenciaram o adensamento dos dados coletados, uma vez que novas entrevistas não ofereceram contribuições adicionais significativas para análise, discussão e conclusão do trabalho. (Minayo, 2010).

Para a composição da amostra, a organização do empreendimento indicou o primeiro empreendedor a ser entrevistado e este, por sua vez, indicou outros e assim sucessivamente, na modalidade "bola de neve". Alguns cuidados foram tomados nas entrevistas, como execução in loco com questionários semiestruturados, registro por gravação para transcrição (Merrian, 1998; Denzin, 1978; Creswell, 2010). As entrevistas foram realizadas no mês de setembro/outubro de 2019 nos empreendimentos das aceleradoras mencionadas.

A análise dos dados coletados contou com a aplicação do modelo de pontuação ponderada, que pode ser utilizado quando se quer definir ou avaliar uma lista de fatores subjetivos relevantes para uma determinada explicação. Situação em que cada fator é submetido a um julgamento para atribuição de um peso, que por sua vez é confrontado (multiplicado) com uma nota refletindo a realidade vivenciada naquele fator. O somatório dessas multiplicações dará o score final. (BALLOU, 2006); (SLACK e outros, 2009).

A matriz de ponderação utilizada seguiu a orientação dos autores mencionados, considerando os seguintes passos: (i) identificação de fatores ou utilização de categorias teóricas validadas, para levantamento da competência; (ii) atribuição da relevância relativa de cada fator (Peso de 0 a 6); (iii) atribuição de nota (ponderação de 0 a 6) para a realidade vivenciada perante cada fator; (iv) multiplicação de cada nota pelo respectivo peso e totalização. 
Com outras palavras os autores afirmam que este modelo é muito presente na literatura e mostra-se útil para ponderar características que explicam um problema, levando em conta qualquer atributo que o respondente julgar importante para a explicação.

\section{ANÁLISE E DISCUSSÃO}

A perspectiva de análise deste estudo considera a identificação de expectativas de empreendedores em relação ao domínio de competências da força de trabalho no negócio da startup. Nessa linha, as discussões teóricas e a análise de dados apresentados nas próximas seções procuram estabelecer um paralelo entre as categorias teóricas de competências tomadas como referência e percepção sobre os atributos dessas categorias na visão dos empreendedores entrevistados.

\subsection{Descrição estatística do perfil dos respondentes}

Embora não seja o objeto central do presente estudo, apresentamos, subsidiariamente, um panorama sobre o perfil do empreendedor da amostra abordada, de modo a permitir uma visão mais contextualizada da percepção sobre os elementos de competência preponderantes na escolha de candidatos a um posto de trabalho em uma startup. Dentre os aspectos revelados na tabulação dos dados, cuja memória de cálculos encontra-se em poder dos autores, aspectos de interesse podem ser visualizados, donde se pode destacar:

Gráfico 1 - Faixa Etária Empreendedores 


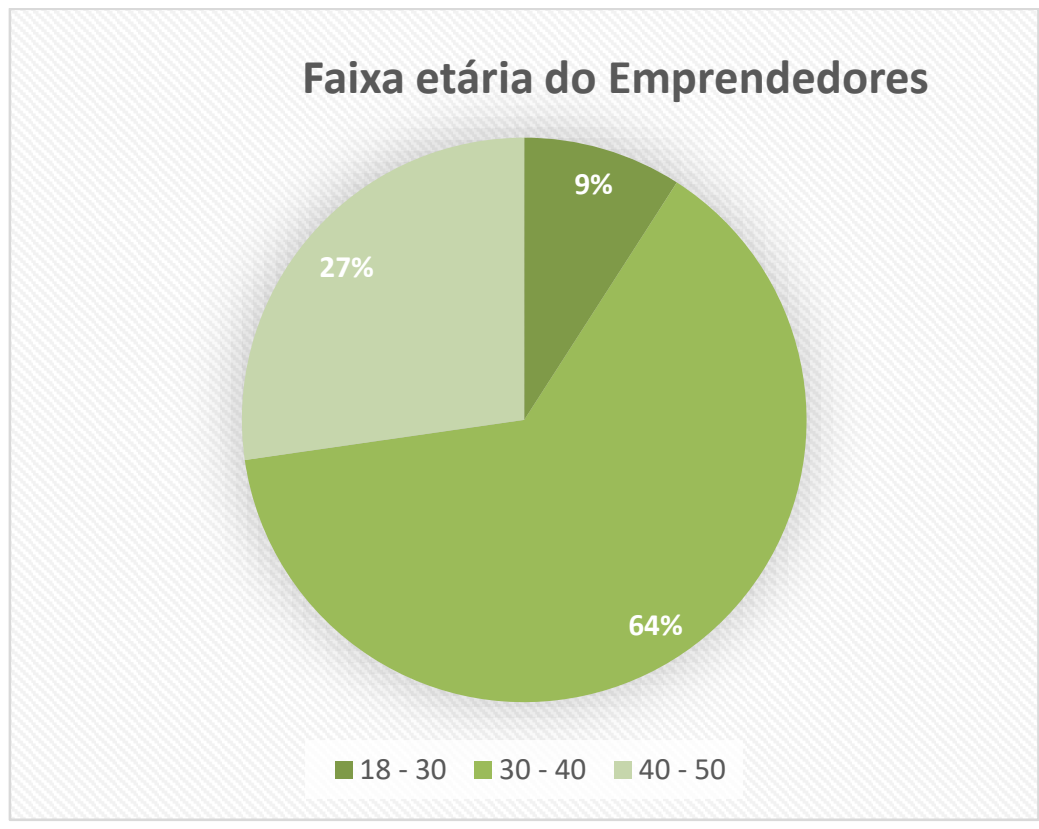

Fonte: elaboração dos autores

Como se pode verificar no gráfico, 64\% dos respondentes são jovens entre 30 e 40 anos de idade. Seria de se indagar se isso pode explicar, pelo menos em parte, o vigor com que esses empreendedores se dedicam a seus negócios.

Gráfico 2 - Outras Experiências Relevantes dos Empreendedores na Área do Negócio.

\section{OUTRAS EXPERIENCIAS \\ RELEVANTES DOS \\ EMPREENDEDORES NA AREA}

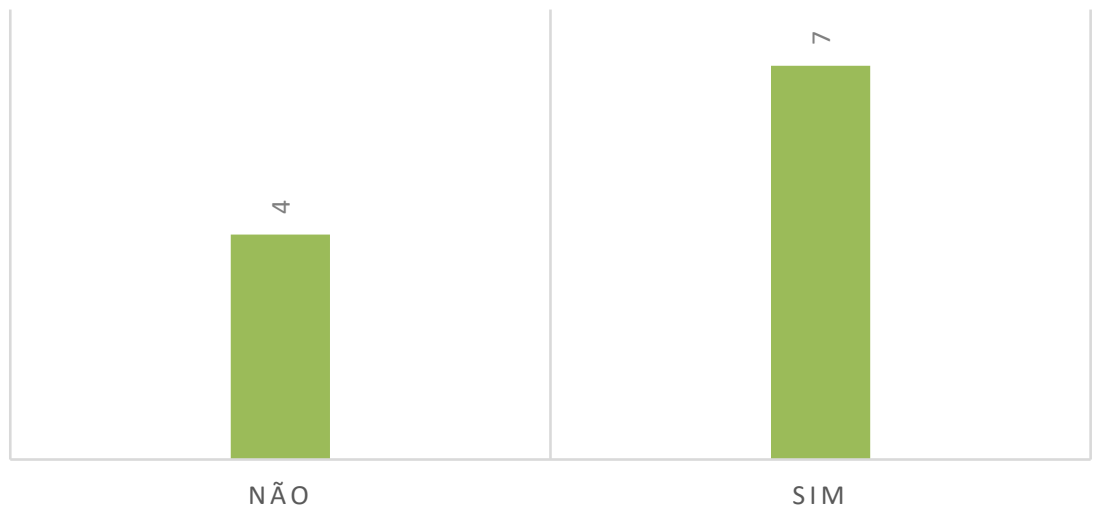

Fonte: elaboração dos autores 
A ilustração gráfica revela que aproximadamente $64 \%$ dos entrevistados têm experiências importantes na área onde atuam. Nas manifestações espontâneas dos respondentes ficou evidenciado que essas experiências foram adquiridas por força de empregos anteriores em outras empresas, pelo trabalho em empreendimento familiar ou por estágios decorrentes de cursos de formação.

Gráfico 3 - Quantidade de Negócios já criados pelo Empreendedor.

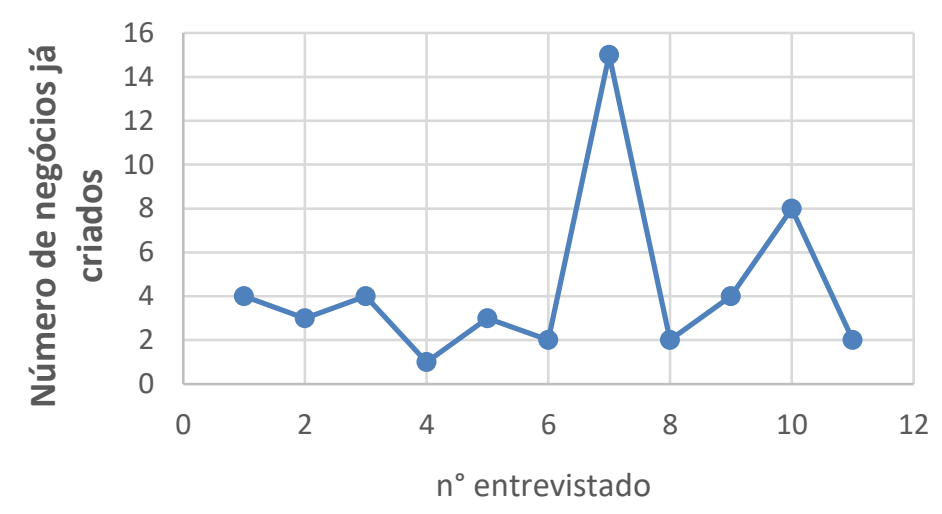

Fonte: elaboração dos autores.

O gráfico $\mathrm{n}^{0} 3$ mostra uma elevada média de criação de negócios pelo empreendedor de startup, revelando uma certa inquietação desses empreendedores no que diz respeito a tentativas de empreender.

Gráfico 4 - Formação dos Pais dos Empreendedores

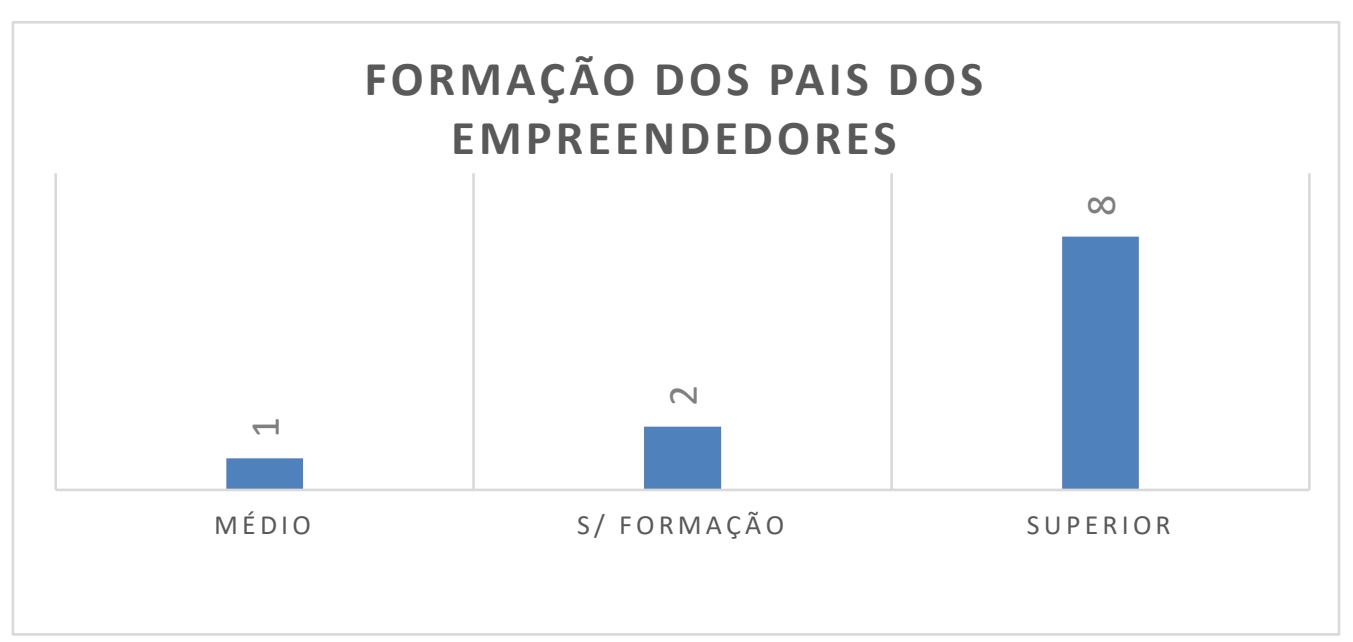

Fonte: elaboração dos autores. 
Essa ilustração mostra que próximo de $73 \%$ dos empreendedores que compuseram a amostra vêm de famílias cujos pais tem formação superior. Em alguns dizeres dos entrevistados isso parece exercer influência no nível de formação dos empreendedores representados na amostra.

Gráfico 5 - Número de Familiares Empreendedores

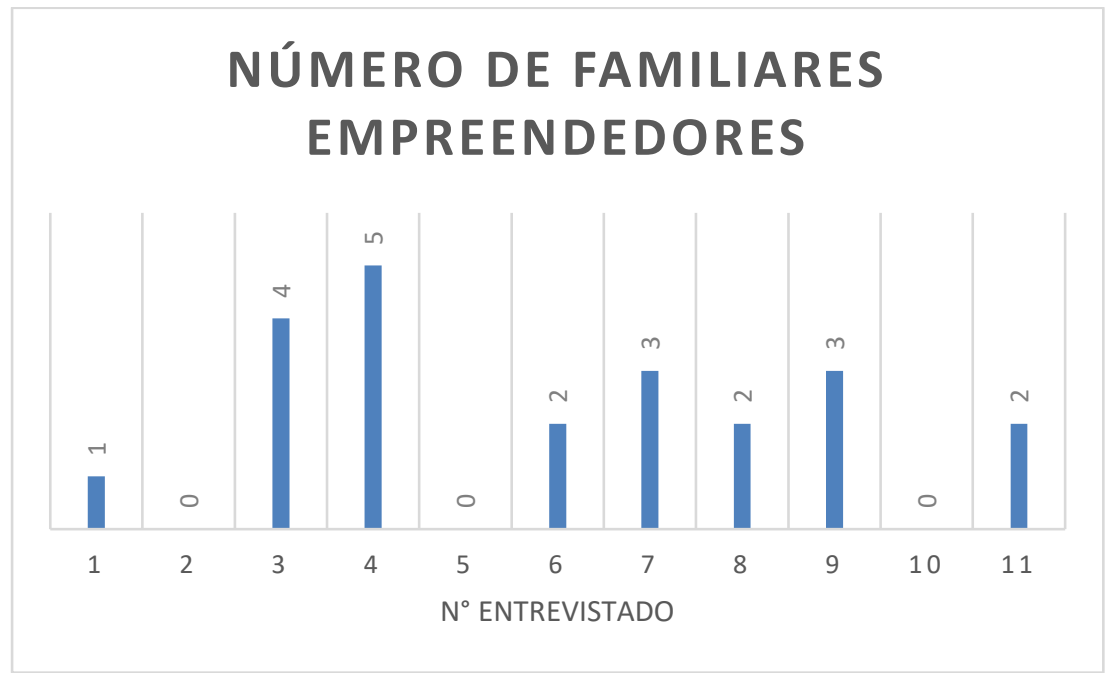

Fonte: elaboração dos autores.

Em média, os entrevistados têm 2 familiares também empreendedores. Seria de se indagar sobre a possível influência do ambiente familiar na percepção do empreendedor de startup sobre as questões relativas a seu negócio.

Gráfico 6 - Número de Colaboradores.

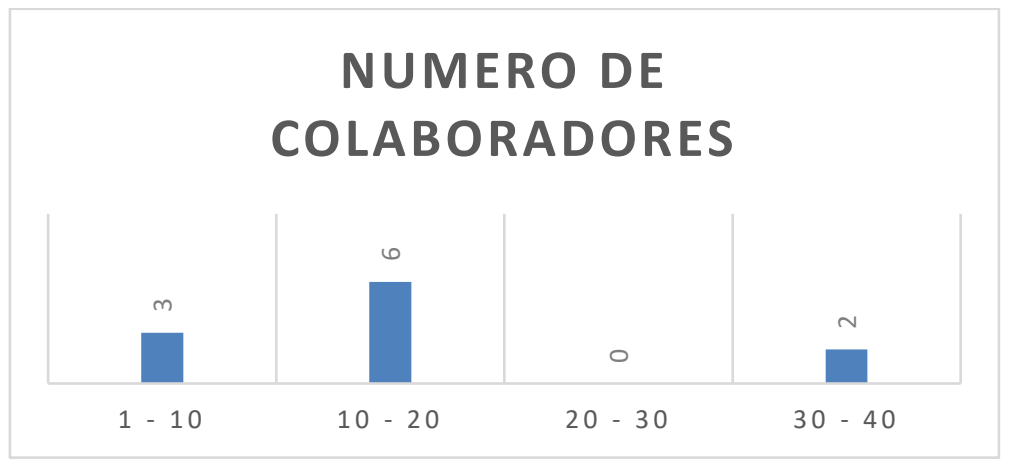

Fonte: elaboração dos autores.

A ilustração oferece uma visão otimista do potencial de ocupação no negócio das startups e mostra que $55 \%$ dos entrevistados ocupam entre 10 a 20 colaboradores. 
Gráfico 7 - Fontes de Financiamento.

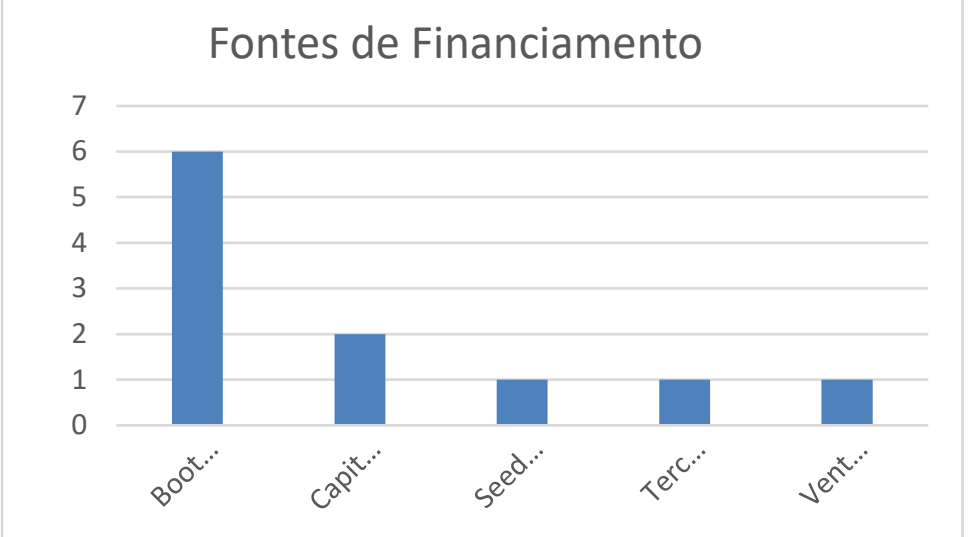

Fonte: elaboração dos autores.

$73 \%$ dos entrevistados iniciaram seus negócios sem grandes investimentos financeiros, utilizando seus próprios recursos de natureza material ou recursos financeiros próprios. Capital semente para sustentar o negócio até sua capacidade de se manter, capital de risco completam o portfólio.

\section{2 PONDERAÇÃO QUALITATIVA DAS CATEGORIAS DE}

\section{COMPETENNCIAS}

Sintonizado com o objetivo do estudo e tomando por base a categorização agregada de Spencer \& Spencer (1993), a tabela a seguir, apresenta o resumo dos pontos centrais dessa discussão. Oportunidade em que se reproduz os principais conjuntos de componentes das competências esperadas pelos empreendedores de startups no processo de seleção de um candidato ao trabalho naquele tipo de empreendimento.

Tabela 1. Ponderação qualitativa atribuída pelos respondentes aos Componentes de Competência de Spencer \& Spencer.

\begin{tabular}{|c|c|c|c|}
\hline \multicolumn{4}{|c|}{ Modelo de competências genéricas de Spencer \& Spencer } \\
\hline Categorias & Componentes & $\begin{array}{c}\text { Score médio* } \\
\text { (dos } 11 \\
\text { respondentes) }\end{array}$ & $\begin{array}{l}\text { Score da } \\
\text { Categoria * }\end{array}$ \\
\hline \multirow{4}{*}{$\begin{array}{c}1 \text { grupo de } \\
\text { conquista e ação }\end{array}$} & Orientação para Resultado & 22,55 & \multirow{4}{*}{21,52} \\
\hline & $\begin{array}{l}\text { Preocupação com qualidade e } \\
\text { segurança nos pedidos }\end{array}$ & 24,09 & \\
\hline & Iniciativa & 19,82 & \\
\hline & Busca de Informação & 19,64 & \\
\hline \multirow{2}{*}{$\begin{array}{l}2 \text { grupo de ajuda e } \\
\text { serviço }\end{array}$} & Compreensão Interpessoal & 20,18 & \multirow{2}{*}{22,45} \\
\hline & Orientação de Serviço ao Cliente & 24,73 & \\
\hline & Impacto e Influencia & 21,36 & 20,60 \\
\hline
\end{tabular}




\begin{tabular}{|c|c|c|c|}
\hline \multirow{2}{*}{$\begin{array}{l}3 \text { grupo de impacto } \\
\text { e influência }\end{array}$} & Consciência Organizacional & 23,00 & \\
\hline & Formação de Relações e Contatos & 17,45 & \\
\hline \multirow{4}{*}{$\begin{array}{c}4 \text { grupo de } \\
\text { competências } \\
\text { gerenciais }\end{array}$} & Desenvolvimento de Terceiros & 18,27 & \multirow{4}{*}{21,75} \\
\hline & Assertividade & 21,00 & \\
\hline & Trabalho em equipe e cooperação & 26,91 & \\
\hline & Liderança de Equipe & 20,82 & \\
\hline \multirow{3}{*}{$\begin{array}{l}5 \text { grupo de } \\
\text { competências } \\
\text { cognitivas }\end{array}$} & Pensamento Analítico & 19,64 & \multirow{3}{*}{19,31} \\
\hline & Pensamento Conceitual & 19,55 & \\
\hline & $\begin{array}{l}\text { Experiência Técnica/ Profissional e } \\
\text { Gerencial }\end{array}$ & 18,73 & \\
\hline \multirow{4}{*}{$\begin{array}{c}6 \text { grupo de } \\
\text { efetividade pessoal }\end{array}$} & Autocontrole & 19,91 & \multirow{4}{*}{21,98} \\
\hline & Autoconfiança & 21,73 & \\
\hline & Flexibilidade & 23,18 & \\
\hline & Compromisso Organizacional & 23,09 & \\
\hline
\end{tabular}

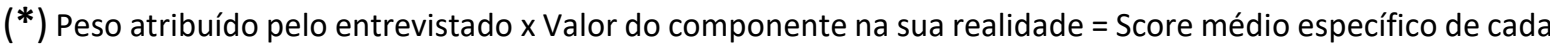
componente. $(* *)$ Média dos Scores específicos = Score da categoria

Fonte: elaboração dos autores - adaptação do Dicionário de Competências de Spencer e Spencer (1993).

Os resultados obtidos no levantamento revelaram a homogeneidade da percepção dos entrevistados em relação aos elevados pesos atribuídos por eles aos grupos (categorias) teóricos utilizados. Essa regularidade permite inferir a aplicabilidade do modelo teórico tomado por referência para identificação e avaliação de competência no ambiente de negócio da startup.

Ainda sob esse raciocínio, fica evidente a preocupação dos gestores entrevistados em melhorar a sintonia entre os grupos teóricos expostos na entrevista e os esforços envidados por eles para o aprimoramento de suas equipes.

No momento em que se abordou os componentes de competência do grupo 2 (Grupo de ajuda e serviço), todos os entrevistados atribuíram significativa importância (peso elevado) e três deles se referiram ao elemento "fidelidade", acrescentando essa condição de competência ao modelo exposto. No dizer de um deles: "fidelidade é tudo nesse negócio".

Embora essa manifestação não tenha sido reivindicada e represente quase $30 \%$ dos entrevistados, a sua discussão não foi esclarecedora o bastante para elucidar a questão do seu relacionamento com a categoria teórica explorada, o que pode sugerir sua inclusão em eventual investigação futura.

Analisando o resultado obtido com a exposição dos componentes de competência do grupo 5 (Grupo de competências cognitivas) observou-se que também obtiveram pesos elevados, o que significa dizer que tais atributos de competência têm grande importância na visão dos respondentes. No entanto, a avaliação dessa categoria foi prejudicada pelo valor atribuído a seus componentes na realidade vivenciada pelo entrevistado.

Em linhas gerais, os valores atribuídos aos componentes de competência explorados, em razão da realidade vivenciada pelo gestor entrevistado, foram menores que os pesos imputados a esses mesmos componentes. A associação dessa informação com o conteúdo dos argumentos utilizados na entrevista, parecem indicar o reconhecimento dos entrevistados da existência de uma lacuna entre o grau de competência disponível nos seus quadros expectativa 
que eles têm de um grau de competência ideal.

Via de regra, o candidato ao trabalho em uma startup surge por indicação, mas os entrevistados reconhecem a necessidade de desenvolver competências nos campos técnicogerencial e atitudinal. Isso pereceu ficar patente nas manifestações dos entrevistados ao deixarem emergir preocupações com a precariedade dos pretendentes em relação aos mecanismos de gestão e ao enfatizar a importância deles inspirarem virtudes como confiança e fidelidade.

Impõe-se comentar, ainda, a preocupação evidenciada pelos respondentes com o aumento das pressões por formação de competências que extrapolem as dimensões técnica e atitudinal, mas alcancem também a dimensão gerencial. Tais pressões advêm de patrocinadores (financiadores), aceleradores e outros steakholders que gravitam no entorno da startup.

\section{CONSIDERAÇÕES FINAIS}

Como primeira consideração, a referência teórica deste estudo permite constatar a ocorrência de uma diversidade de concepções teóricas a respeito da competência, o que, em certa medida parece contribuir para dificultar sua identificação e avaliação. Apesar disso, desde os estudos que marcaram a gênese da reflexão sobre competências, parte significativa da literatura converge para aquela definição de competência expressa por meio da sigla "CHA", representando Conhecimento, Habilidade e Atitude. Essa convergência parece permitir uma harmonização conceitual suficiente para atenuar eventuais divergências e conciliar modelos de avaliação.

Assim, na medida em que a necessidade de identificar, desenvolver e avaliar competências vem se impondo paulatinamente na pauta das organizações, pode-se observar o surgimento de valiosos instrumentos de mensuração representados por construtos, categorias e escalas que possam refletir o grau de competência e seu impacto no desempenho da organização.

Nesse encadeamento o estudo procurou testar o modelo proposto por Spencer \& Spencer (1993) numa amostra que pudesse refletir a realidade de uma organização do tipo startup, chegando à conclusão da viabilidade de aplicação do modelo nesta situação. De fato, a estabilidade dos "scores" dos componentes de competência, numa faixa estreita de variação, pode confirmar esta constatação.

Uma outra dedução, diz respeito ao reconhecimento de que os atributos de natureza atitudinal interferem substancialmente na escolha de um candidato a um posto de trabalho na startup. A elevação, ainda que discreta, na pontuação do grupo 2 do modelo testado, associado às colocações livremente manifestadas no exercício empírico realizado, encorajam esta afirmação.

Na mesma linha, partindo dos indícios revelados na pontuação do grupo 5, que trata das competências de natureza cognitivas, permitimo-nos inferir a precariedade com que os gestores de startups lidam no que se refere às competências gerenciais, à capacidade analítica e ao domínio teórico dos seus potenciais colaboradores.

O desafio que fica claro para as startups, ao que parece, é lidar com essas fragilidades, absorvendo, cada vez mais, mecanismos típicos da gestão dos negócios. Dentre as providências pertinentes, essa seria uma das medidas enfatizadas e estimuladas pela aceleradora, de acordo com manifestações espontâneas de alguns entrevistados. 
Uma outra consideração a destacar, diz respeito à validação das conjecturas teórica e empírica que deram referência ao objeto estudado. O método do caso e a limitação no tamanho da amostra, não obstante as restrições em relação à possibilidade de generalização, poderá atender situações particulares onde o interesse do estudo incidir.

As limitações desta pesquisa podem ser compensadas por outras iniciativas merecedoras de estudos futuros que pudessem ampliar o seu escopo, de maneira a permitir generalização. Uma dessas iniciativas poderia ser o estudo da adequação semântica do modelo teórico tomado por referência à linguagem restrita ao grupo profissional que atua numa startup.

De qualquer forma, as variadas perspectivas que possam ser adotadas para observar e analisar os problemas que se pode estabelecer a partir do estudo das competências, recomendam investigações futuras mais aprofundados em suas diversificadas facetas, de modo a permitir um olhar mais apurado sobre a complexa tarefa de examinar o fenômeno da competência requerida no mundo de negócios da startup.

\section{REFERÊNCIAS}

ACS, Z.J. and AUDRETSCH, D.B. (1988), "Innovation in large and small firms: an empirical analysis", The American Economic Review, Vol. 78 No. 4, pp. 678-690.

BALLOU, Ronald H. Gerenciamento da cadeia de suprimentos: logística empresarial. Porto Alegre: Bookman, 2006.

BLANK, S. (2010), "What's a startup? First principles", available at: http://steveblank.com/2010/01/25/ whats-a-startup-first-principles/ (accessed December 15, 2015).

BOOG, G, G. (1991) O desafio da competência: como sobreviver em um mercado cada vez mais seletivo e preparar sua empresa para o próximo milênio. Best Seller: São Paulo

CRESWELL, J. W. Projeto de pesquisa: métodos qualitativo, quantitativo e misto. 2. ed. Porto Alegre: Bookman, 2010.

DAVIS, L. The work activity briefing:A model for workplace learning and leadership. Brisbane: 2000.

DENZIN, N. K., LINCOL, Y. S. (2005) Handbook of qualitative research. 3. ed. Thousand Oaks: Sage Publications

DURAND, Thomas. Forms of incompetence. Apresentado em: International Conference on Competence Based Management, Oslo: 1988.

ESTEVE-Pérez, S. and RODRÍGUEZ, D. (2013), "The dynamics of exports and R\&D in SMEs", Small Business Economics, Vol. 41 No. 1, pp. 219-240.

FLEURY, A. C. C.; FLEURY, M. T. L. Estratégias empresariais e formação de competências. São Paulo: Atlas, 2000.

FREEMAN, J. and ENGEL, J.S. (2007), "Models of innovation: startups and mature corporations", California Management Review, Vol. 50 No. 1, pp. 94-119.

FREEMAN, J., CARROLL, G.R. and HANNAN, M.T. (1983), "The liability of newness: age dependence in organizational death rates", American Sociological Review, Vol. 48, pp. 692-710.

GIL, A. C. (2008). Métodos e técnicas de pesquisa social. 6. ed. São Paulo: Atlas. 
GOLDENBERG, M. (2004). A arte de pesquisar: como fazer pesquisa qualitativa em Ciências Sociais. 8.ed. Rio de Janeiro: Record.

GRUBER, M., MACMILLAN, I.C. and THOMPSON, J.D. (2008), "Look before you leap: market opportunity identification in emerging technology firms", Management Science, Vol. 54 No. 9, pp. 1652-1665.

HUNT, R.A. (2013), "Entrepreneurial tweaking: an empirical study of technology diffusion through secondary inventions and design modifications by start-ups", European Journal of Innovation Management, Vol. 16 No. 2, pp. 148-170.

INOVABRA acesso sítio www.inovabra.com.br em 01/09/2019. Routledge.

Lacey, H. (1999) Is science value free? Values and scientific understanding. London:

LE BOTERF, Guy Desenvolvendo a competência dos profissionais. Porto Alegre: Artmed, 2003.

LEVY LEBOYER, C. Gestión de las competencias. Barcelona: 1997.

LUGER, M. I., \& KOO, J. (2005). Defining and tracking business start-ups. Small Business Economics, 24(1), 17-28.

MCCLELLAND, D. C.; SPENCER, L. M. Competency assessment methods: history and state of the art. Hay McBer Research Press, 1990.

MCCLELLAND, D. C. Testing for competence rather than for intelligence. American Psychologist, v 28 - 1-14, 1973.

MERRIAM, S. B.(1998). Qualitative research and case study applications in education: revised and expanded from case study research in education. 2.ed. San Francisco: Jossey-Bass Education Series and The Josey-Bass Higher Education Series.

MINAYO, M. C. S. (2010). O desafio do conhecimento: pesquisa qualitativa em saúde. 12. ed. São Paulo: Hucitec

MOSCOVICI, F. Equipes dão certo. Rio de Janeiro: 1994.

OECD (2010), High-Growth Enterprises: What Governments Can Do to Make a Difference, OECD Studies on SMEs and Entrepreneurship, OECD Publishing, Paris, https://doi.org/10.1787/9789264048782-en.

PARRY, S. B. The quest for competencies. Training, v 33, n.7, p. 48-54, 1996.

PRAHALAD, C.K. e HAMEL, Gary. The Core Competence of the Corporation. Harvard Business Review, p. 3-15, 1990.

PRAHALAD, C. K.; HAMEL, G. Competindo pelo futuro: estratégias inovadoras para obter o controle do seu setor e criar os mercados de amanhã. Rio de Janeiro: Campus. 2005.

SANDBERG, J. Human competence at work. Goteborg: 1996.

SCHUMPETER, J.A. (1934), The Theory of Economic Development: An Inquiry into Profits, Capital, Credit, Interest, and the Business Cycle, Harvard University Press, Cambridge, MA.

SLACK, Nigel. CHAMBERS, Stuart; JOHNSTON Robert.Tradução de Henrique Luiz Corrêa. Administração da produção. São Paulo: Atlas, 2009. 
SPARROW, P. R. e BOGNANNO, M. Competency requirement forecasting: Issues for international selection and assessment. London: Routledge, p. 57-69, 1994.

SPENCER, L.M.; SPENCER, S. M. Competence at work: models for superior performance. New York: John Wiley \& Sons, 1993.

TEECE, D.J. (2010), “Business models, business strategy and innovation”, Long Range Planning, Vol. 43 No. 2, pp. 172-194.

VIEIRA, M. M. F., ZOUAIN, D. M. (2004). Pesquisa qualitativa em Administração. Rio de Janeiro: Editora FGV.

ZARIFFIAN, Philippe. Objetivo competência: por uma nova lógica. Tradução: Maria Helena C. V. Trylinski. São Paulo: Atlas, 2008.

ZEUCH, M. (Ed.). (2016). Handbook of human resources management. Springer Berlin Heidelberg. 